\title{
The properties of innovated mortars utilizing secondary raw material
}

\author{
M. Č́chová ${ }^{1}$, D. Koňáková ${ }^{1}$, E. Vejmelkokvá ${ }^{1}$, M. Keppert ${ }^{1}$, \\ P. Reiterman ${ }^{2} \&$ R. Černý ${ }^{1}$ \\ ${ }^{1}$ Department of Materials Engineering and Chemistry, \\ Faculty of Civil Engineering, \\ Czech Technical University in Prague, Czech Republic \\ ${ }^{2}$ Experimental Centre, Faculty of Civil Engineering, \\ Czech Technical University in Prague, Czech Republic
}

\begin{abstract}
This paper studied lime mortars containing waste brick powder. The powder originates from grinding of thermal insulating bricks. The aim of the study is to find out appropriate application of this secondary raw material. For this purpose we tried to replace silica sand by the brick powder in different quantities $(10 \%, 30 \%$ and $50 \%$ of weight). An influence of the brick powder replacement is determined through the properties of special mortars, which were compared with a pure lime mortar (with no powder replacement). Specifically in this article experimental methods and results of basic physical properties, pore structure characterization, mechanical properties and hydric transport abilities (water vapour as well as liquid water transport) are described.

Keywords: lime plaster, basic physical properties, water vapor transport, liquid water transport.
\end{abstract}

\section{Introduction}

In civil engineering and mainly materials engineering there is a trend to improve traditional building materials. One of the main efforts of the whole world is to improve environmental and economic parameters. We have combined those two perspectives - classic pure lime plaster (traditional building material) with a content of a finely ground brick (waste material). In prior articles the utilization of finely ground waste brick powder as pozzolanic component of lime based 
mortars and plasters were studied $[1,2]$. In this article new types of plasters with brick ash are investigated; quartz sand was replaced by a finely ground brick. 10, 30 and $50 \%$ replacement and the reference lime plaster were studied. The fine ground brick is a waste originating in grinding process in production of thermal insulation ceramic brick blocks [3].

Measurement methods and experimental results are described and discussed in this study. Basic physical properties (by water vacuum saturation and by helium pycnometry), mechanical characteristic (bending and compressive strength), moisture properties (transport of water vapor - cup methods and transport of liquid water - sorptivity) and thermal parameters are presented in detail.

\section{Material}

The composition of the studied plasters is shown in Table 1. The fine ground brick (brick dust) is produced by company Heluz cihlářský průmysl, v.o.s. (Czech Republic) - it is a waste material produced by grinding of calibrated ceramic thermal insulation brick blocks. The used slaked lime CL $90 \mathrm{~S}$ is produced by company Vápenka Čertovy schody a.s. Three fractions of natural quartz sand were used as filler. In this article replacement of the sand by the brick ash was studied.

Table 1: The composition of studied plasters.

\begin{tabular}{|c|c|c|c|c|c|c|}
\hline \multirow[b]{2}{*}{ Material } & \multirow{2}{*}{$\begin{array}{l}\text { Lime } \\
{[\mathrm{kg})}\end{array}$} & \multirow{2}{*}{$\begin{array}{c}\text { Brick } \\
\text { ash } \\
\text { (kg) }\end{array}$} & \multicolumn{3}{|c|}{ Sand (kg) } & \multirow{2}{*}{$\begin{array}{c}\text { Water } \\
{[1]}\end{array}$} \\
\hline & & & $0.3-0.8$ & $0.6-1.2$ & $1.0-4.0$ & \\
\hline CKR & 3.75 & 0.000 & 3.750 & 3.750 & 3.750 & 3.8 \\
\hline CKA & 3.75 & 1.125 & 3.375 & 3.375 & 3.375 & 4.1 \\
\hline CKB & 3.75 & 3.375 & 2.625 & 2.625 & 2.625 & 4.5 \\
\hline CKC & 3.75 & 5.625 & 1.875 & 1.875 & 1.875 & 5.5 \\
\hline
\end{tabular}

The solely lime plaster labeled as CKR was used as the reference. Modified plasters with an increasing content of ceramics were labeled as CKA to CKC (Table 1). The consistency of mortars was tested by standard flow test [4].

\section{Experimental methods}

\subsection{Basic physical properties}

The tested basic physical properties were the bulk density $\rho\left(\mathrm{kgm}^{-3}\right)$, matrix density $\rho_{\text {mat }}\left(\mathrm{kgm}^{-3}\right)$ and open porosity $\psi_{0}(\%)$. These properties were measured using the water vacuum saturation method [5] and helium pycnometry.

The water vacuum saturation was measured on samples of dimensions $50 \times 50 \times 50 \mathrm{~mm}$. These samples were dried at $80^{\circ} \mathrm{C}$ and weighed. After those samples were vacuum saturated by water, it means that samples given to the 
evacuated desiccator for at least 48 hours and weighed again in the saturated state with the help of Archimedes scales.

The matrix density can be determined also by helium pycnometry. This experiment was carried out by the device "Pycnomatic ATC" produced by company Thermo. This device has analogous principle as classic pycnometry.

\subsection{Mechanical properties}

Mechanical properties are measured on prisms of dimensions 40 × 40 × $160 \mathrm{~mm}$. The compressive and bending strength were determined according to the standard (ČSN EN 1015:11 [6]). The bending strength was determined by the device "MTS 100". The measurement was made by the classic tree-point burdening. The distance between supports was $100 \mathrm{~mm}$. The compressive strength was determined by the device "EU 40" and on half-beams from the bending strength measurement.

\subsection{Moisture properties}

\subsubsection{Transport of water vapor}

The water vapor diffusion coefficient $D\left(\mathrm{~m}^{2} \mathrm{~s}^{-1}\right)$ was measured by the cup method - the dry and wet cup methods [7]. The cups were placed in a controlled climatic chamber with $50 \%$ relative humidity. In the dry cup method silica gel was used, while in the wet cup method water was placed in the cup. The cups were periodically weighed. The water vapor diffusion coefficient $D\left(\mathrm{~m}^{2} \mathrm{~s}^{-1}\right)$ was calculated from the measured data according to the equation:

$$
D=\frac{\Delta m \cdot d \cdot R \cdot T}{S \cdot \tau \cdot M \cdot \Delta p_{p}}
$$

where $\Delta m$ is the amount of water vapor diffused through the sample $(\mathrm{kg}), d$ is the sample thickness (m), $R$ is the universal gas constant, $T$ is the thermodynamic temperature $(\mathrm{K}), S$ is the sample area $\left(\mathrm{m}^{2}\right), \tau$ is the period of time corresponding to the transport of water vapor $\Delta m(\mathrm{~s}), M$ is the molar mass of water, and $\Delta p_{p}$ $(\mathrm{Pa})$ is the difference between the partial water vapor pressure in the air under and above the specific specimen surface.

The water vapor diffusion resistance factor $\mu(-)$ was determined as

$$
\mu=\frac{D_{a}}{D}
$$

where $D_{a}\left(\mathrm{~m}^{2} \mathrm{~s}^{-1}\right)$ is the diffusion coefficient of water vapor in the air.

\subsubsection{Transport of liquid water}

The moisture diffusivity $\kappa\left(\mathrm{m}^{2} \mathrm{~s}^{-1}\right)$ was determined by absorption experiment. The studied plaster specimens $(50 \times 50 \times 50 \mathrm{~mm})$ were immersed $1-2 \mathrm{~mm}$ to water and the mass was recorded by a digital scale and a computer program. The water absorption coefficient $A\left(\mathrm{kgm}^{-2} \mathrm{~s}^{-1 / 2}\right)$ was then calculated using the equation

$$
i=A \cdot \sqrt{t}
$$


where $i\left(\mathrm{~kg} \mathrm{~m}^{-2}\right)$ is the cumulative water absorption and $t$ is the time from the beginning of the suction experiment (s). The water absorption coefficient was used for the calculation of the apparent moisture diffusivity $\kappa\left(\mathrm{m}^{2} \mathrm{~s}^{-1}\right)$ according

$$
\kappa \cong\left(\frac{A}{w_{s a t}}\right)^{2}
$$

where $\mathrm{w}_{\mathrm{sat}}\left(\mathrm{kgm}^{-3}\right)$ is the saturated moisture content. [8]

\subsection{Thermal properties}

The thermal conductivity $\lambda\left(\mathrm{Wm}^{-1} \mathrm{~K}^{-1}\right)$ and specific heat capacity $c\left(\mathrm{Jkg}^{-1} \mathrm{~K}^{-1}\right)$ were determined by the device ISOMET 2104 - Applied Precision [9]. Isomet 2104 is a portable and nonstationary device.

\section{Experimental results}

\subsection{Basic physical properties}

The final values of the basic physical properties measured by the water vacuum saturation method are given in Table 2. For comparison these properties were measured also by the helium pycnometry (Table 3 ).

Table 2: The basic physical properties of the studied plasters by Archimedes scales.

\begin{tabular}{|c|c|c|c|}
\hline \multirow{2}{*}{ Material } & \multicolumn{3}{|c|}{ Water vacuum saturation } \\
\cline { 2 - 4 } & $\rho\left(\mathrm{kg} / \mathrm{m}^{3}\right)$ & $\rho_{\text {mat }}\left(\mathrm{kg} / \mathrm{m}^{3}\right)$ & $\psi_{0}(\%)$ \\
\hline CKR & 1699 & 2328 & 27.0 \\
\hline CKA & 1628 & 2392 & 32.0 \\
\hline CKB & 1572 & 2469 & 36.3 \\
\hline CKC & 1479 & 2487 & 40.8 \\
\hline
\end{tabular}

Table 3: The basic physical properties of the studied plasters by helium pycnometer.

\begin{tabular}{|c|c|c|c|}
\hline \multirow{2}{*}{ Material } & \multicolumn{3}{|c|}{ Pycnometry } \\
\cline { 2 - 4 } & $\rho\left(\mathrm{kg} / \mathrm{m}^{3}\right)$ & $\rho_{\text {mat }}\left(\mathrm{kg} / \mathrm{m}^{3}\right)$ & $\psi_{0}(\%)$ \\
\hline CKR & 1652 & 2576 & 35.9 \\
\hline CKA & 1596 & 2591 & 38.4 \\
\hline CKB & 1561 & 2640 & 40.9 \\
\hline CKC & 1454 & 2660 & 45.4 \\
\hline
\end{tabular}


The vacuum saturation method reported somewhat lower values of porosity since it corresponds to open porosity while the results of helium pycnometry describe the total porosity. The values of the bulk densities decrease with an increasing pozzolanic admixture content. The matrix densities and open porosities increase with increasing pozzolanic admixture content. The value of the open porosity $\psi_{0}$ of plaster CKC in comparison with plaster CKR had decreased by $14 \%$ (water vacuum saturation) and $10 \%$ (helium pycnometer).

\subsection{Mechanical properties}

Table 4 shows the mechanical properties of the studied plasters. By adding the pozzolanic admixture the values of the compressive and bending strengths increase. The results are corresponding to the measured values of open porosity.

Table 4: Mechanical properties of studied plasters.

\begin{tabular}{|c|c|c|}
\hline Material & Bending strength $(\mathrm{MPa})$ & Compressive strength (MPa) \\
\hline CKR & 0.25 & 0.62 \\
\hline CKA & 0.30 & 0.84 \\
\hline CKB & 1.14 & 4.18 \\
\hline CKC & 1.21 & 4.80 \\
\hline
\end{tabular}

\subsection{Moisture properties}

\subsubsection{Transport of water vapor}

Table 5 and 6 show the values of water vapor diffusion parameters of all studied plasters. The values of the water vapor diffusion coefficient $D$ increase with an increasing pozzolanic admixture ratio. The results do correspond to the measured open porosity. The values of the diffusion resistance factor $\mu$ decrease with an increasing pozzolanic admixture ratio.

The value of the water vapor diffusion coefficient $D$ of plaster $\mathrm{CKC}$ in comparison with plaster CKR had increased by $16 \%$ (dry cup) and $18 \%$ (wet cup). The value of the diffusion resistance factor $\mu$ of plaster CKC in comparison with plaster CKR had decreased by $16 \%$ (dry cup) and $18 \%$ (wet cup). The difference between results of dry cup and wet cup method was observed already for other types of materials as well; it is probably due to distortion of wet cup results also by some condensed liquid water transport [10].

Table 5: Water vapor transport properties of the studied plasters (dry - cup).

\begin{tabular}{|c|c|c|c|}
\hline \multirow{2}{*}{ Material } & \multicolumn{3}{|c|}{ Dry - cup } \\
\cline { 2 - 4 } & $\delta(\mathrm{s})$ & $\mathrm{D}\left(\mathrm{m}^{2} \mathrm{~s}^{-1}\right)$ & $\mu(-)$ \\
\hline CKR & $1.53 \mathrm{E}-11$ & $2.11 \mathrm{E}-06$ & 10.85 \\
\hline CKA & $1.64 \mathrm{E}-11$ & $2.25 \mathrm{E}-06$ & 10.56 \\
\hline CKB & $1.76 \mathrm{E}-11$ & $2.42 \mathrm{E}-06$ & 9.50 \\
\hline CKC & $1.83 \mathrm{E}-11$ & $2.51 \mathrm{E}-06$ & 9.16 \\
\hline
\end{tabular}


Table 6: Water vapor transport properties of the studied plasters (wet - cup).

\begin{tabular}{|c|c|c|c|}
\hline \multirow{2}{*}{ Material } & \multicolumn{3}{|c|}{ Wet - cup } \\
\cline { 2 - 4 } & $\delta(\mathrm{s})$ & $\mathrm{D}\left(\mathrm{m}^{2} \mathrm{~s}^{-1}\right)$ & $\mu(-)$ \\
\hline CKR & $1.83 \mathrm{E}-11$ & $2.52 \mathrm{E}-06$ & 9.15 \\
\hline CKA & $2.01 \mathrm{E}-11$ & $2.77 \mathrm{E}-06$ & 8.31 \\
\hline CKB & $2.10 \mathrm{E}-11$ & $2.89 \mathrm{E}-06$ & 7.96 \\
\hline CKC & $2.23 \mathrm{E}-11$ & $3.07 \mathrm{E}-06$ & 7.50 \\
\hline
\end{tabular}

\subsubsection{Transport of liquid water}

The results of the studied plaster's water sorptivity measurements are presented in Table 7. The ability to transport the liquid moisture decreased with an increasing volume of pozzolanic admixture. The value of the water absorption coefficient $A$ of plaster CKC in comparison with plaster CKR had decreased by $31 \%$.

Table 7: Liquid water transport parameters of the studied plasters.

\begin{tabular}{|c|c|c|}
\hline Material & $\mathrm{A}\left(\mathrm{kg} \mathrm{m}^{-2} \mathrm{~s}^{-1 / 2}\right)$ & $\kappa\left(\mathrm{m}^{2} \mathrm{~s}^{-1}\right)$ \\
\hline CKR & 0.2531 & $9.53 \mathrm{E}-07$ \\
\hline CKA & 0.1842 & $3.65 \mathrm{E}-07$ \\
\hline CKB & 0.1800 & $2.43 \mathrm{E}-07$ \\
\hline CKC & 0.1754 & $1.86 \mathrm{E}-07$ \\
\hline
\end{tabular}

\subsection{Thermal properties}

Thermal parameters of the studied plasters are given in Tables 8 and 9 and Figure 1.

Table 8: Thermal properties of the studied materials in the dry state.

\begin{tabular}{|c|c|c|}
\hline Material & $\lambda\left(\mathrm{W} \mathrm{m}^{-1} \mathrm{~K}^{-1}\right)$ & $\mathrm{c}\left(\mathrm{J} \mathrm{kg}^{-1} \mathrm{~K}^{-1}\right)$ \\
\hline CKR & 1.034 & 849 \\
\hline CKA & 0.904 & 886 \\
\hline CKB & 0.732 & 943 \\
\hline CKC & 0.639 & 977 \\
\hline
\end{tabular}

Table 9: Thermal properties of the studied plasters in the saturated state.

\begin{tabular}{|c|c|c|c|}
\hline Material & $\mathrm{w}\left(\% \mathrm{~m}^{3} \mathrm{~m}^{-3}\right)$ & $\lambda\left(\mathrm{W} \mathrm{m}^{-1} \mathrm{~K}^{-1}\right)$ & $\mathrm{c}\left(\mathrm{J} \mathrm{kg}^{-1} \mathrm{~K}^{-1}\right)$ \\
\hline CKR & 28.39 & 2.467 & 950 \\
\hline CKA & 32.06 & 2.462 & 969 \\
\hline CKB & 37.70 & 2.182 & 1090 \\
\hline CKC & 43.89 & 1.728 & 1086 \\
\hline
\end{tabular}




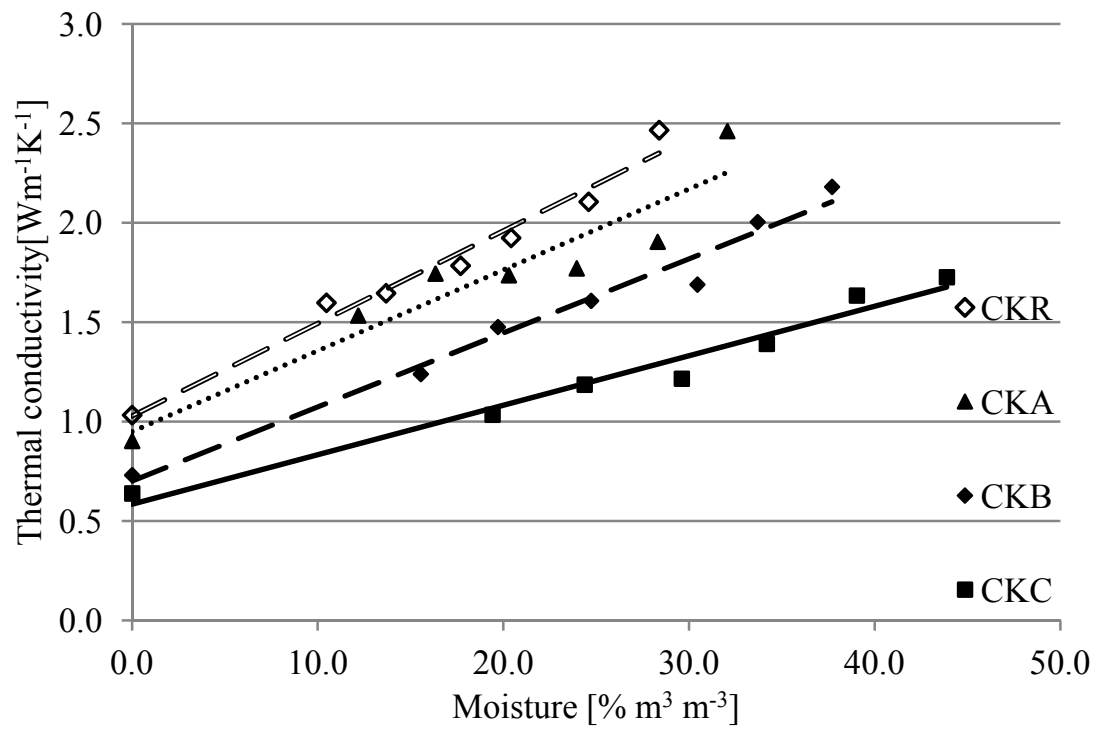

Figure 1: The thermal conductivity of plasters as function of moisture content.

The reference sample $\mathrm{CKR}$ had reached the highest value of the thermal conductivity coefficient. Thus, the special plaster $\mathrm{CKC}$ is the best thermal insulator.

\section{Conclusion}

After adding a finely ground brick admixture to the plaster the open porosity increased. The values of the bulk densities decrease and open porosities increase with increasing pozzolanic admixture content. By adding the pozzolanic admixture the values of the strengths parameters increase. The values of the water vapor diffusion coefficient $D$ increase with an increasing pozzolanic admixture ratio. The results do correspond to the measured open porosity. The values of the diffusion resistance factor $\mu$ decrease with an increasing pozzolanic admixture ratio. Thus, plasters with an admixture of finely ground brick had a worse ability to transport moisture. Also by the thermal properties were also affected. The best thermal insulator seems to be the special plaster $\mathrm{CKC}$ with the highest amount of the finely ground brick admixture.

\section{Acknowledgement}

This research has been supported in the Czech Republic under project SGS13/165/OHK1/3T/11. 


\section{References}

[1] Monika Čáchová, Eva Vejmelková, Martin Kppert, Robert Černý, Infuelnce of Finely Ground Brick on Hydric Properties of Lime Plasters, $4^{\text {th }}$ European Conference of Mechanical Engineering, Paris, France, October 2013, ISBN: 978-960-474-345-2, pp. 117-121.

[2] Monika Čáchová, Eva Vejmelková, Martin Keppert, Robert Černý, Thermal properties of plaster a content of a finely ground brick, $4^{\text {th }}$ International Conference on Fluid Mechanics and Heat \& Mass Transfer, Duborvnik, June 2013, ISBN: 978-960-474-307-0, pp. 123-127.

[3] Monika Čáchová, Properties of plasters with content finely ground brick, Diploma thesis, CTU in Prague, Prague 2013.

[4] ČSN EN 1015-3 - Methods of test for mortar for masonry - Part 3: Determination of consistence of fresh mortar (by flow table), 2000.

[5] Kumaran, M. K.: Moisture Diffusivity of Building Materials from Water Absorption Measurements,IEA Annex 24 Report T3-CA-94/01, Ottawa 1994.

[6] ČSN EN 1015:11 - Determining the strength of hardened mortar bending and compressive, 2000.

[7] ČSN 72 7031: Determination of water vapour diffusion coefficient of building materials by method without temperature gradient, 2001.

[8] ČSN EN 1015-18: Methods of test for mortar for masonry - Part 18: Determination of water absorption coefficient due to capillarity action of hardened mortar, 2003.

[9] Applied Precision - ISOMET. [User manual], Bratislava, 1990.

[10] Robert Černý, Pavla Rovnaníková, Transport Processes in Concrete, London, Spon Press 2002. 